Prepared in cooperation with the South Florida Water Management District

\title{
Hydrodynamic Characteristics and Salinity Patterns in Estero Bay, Lee County, Florida
}

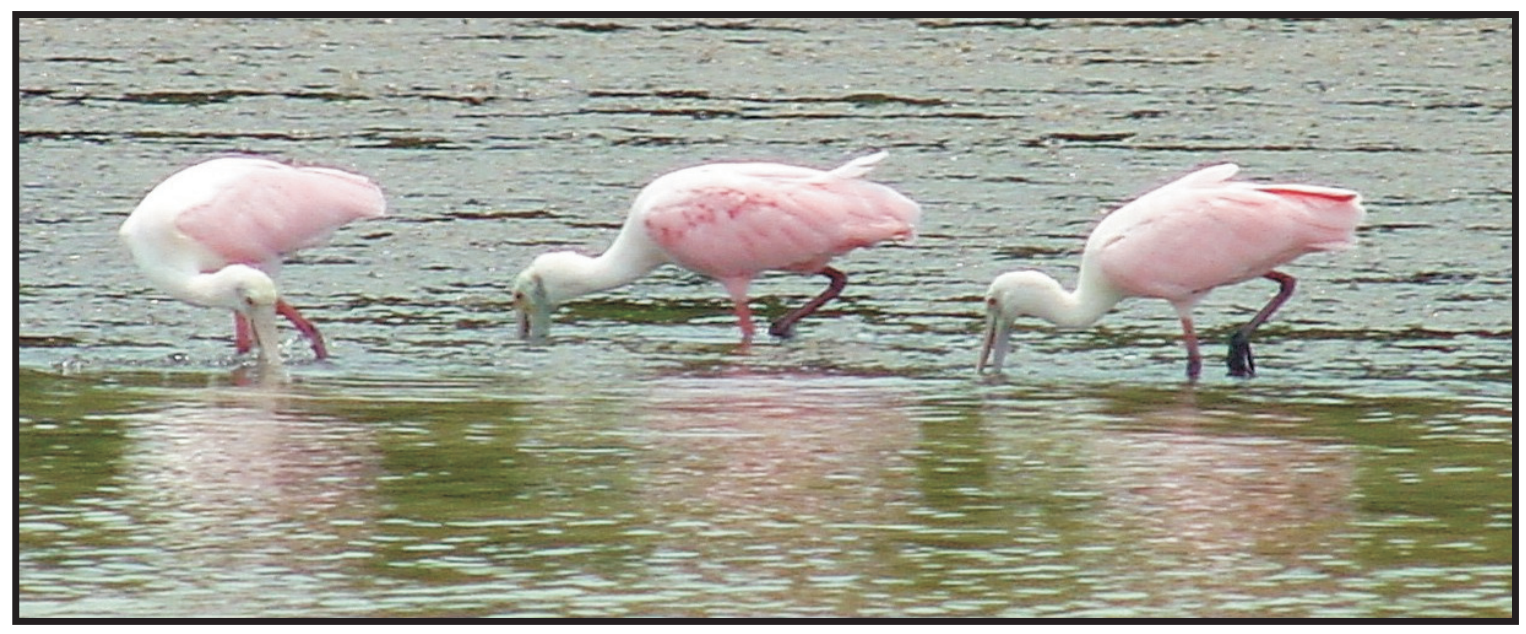

Scientific Investigations Report 2007-5217 
6 Printed on recycled paper 